\title{
ANALISIS DAMPAK UKURAN PERUSAHAAN, OPINI AUDIT, DAN REPUTASI KAP TERHADAP AUDIT DELAY PADA PERUSAHAAN PERTAMBANGAN YANG TERDAFTAR DI BEI PERIODE 2010-2016
}

\author{
Yusi Nur Irmalia, Hidayatul Khusnah, Endah Tri Wahyuningtyas \\ Program Studi Akuntansi, Fakultas Ekonomi \& Bisnis, \\ Universitas Nahdlatul Ulama Surabaya \\ e-mail:yusiirmalia19@gmail.com
}

\begin{abstract}
The purpose of this study was to analyze the firm size, audit opinion, and reputation of public accountant on audit delay. The data used in this research was secondary data, taken from the annual report 2010 to 2016 of mining companies listed at the Indonesia Stock Exchange. The samples consist of 133 firms from 2010 through 2016 and still listed. The analysis tools to test hypothesis are logistic regression analysis by using SPSS 20 with the degree of significance at 0.05 . The empirical result of the study show that the firm size, audit opinion, and reputation of public accountant simultaneously have a positive influence on audit delay. The firm size has no positive effect on audit delay. While audit opinion, and reputation of public accountant have a positive influence on audit delay.
\end{abstract}

Keywords: firm size, audit opinion, reputation of public accountant, and audit delay

\section{PENDAHULUAN}

Perusahaan yang sudah go public diwajibkan untuk menyampaikan laporan keuangan yang disusun sesuai dengan standar akuntansi keuangan yang telah diaudit oleh akuntan publik terdaftar di Badan Pengawas Pasar Modal (Bapepam). Hasil audit atas perusahaan publik mempunyai konsekuensi dan tanggung jawab yang besar. Tanggung jawab yang besar ini memicu auditor bekerja lebih profesional.

Salah satu kriteria profesionalisme auditor adalah ketepatan waktu dalam penyampaian laporan auditnya (Trisnawati dan Estralia, 2008).

Perusahaan yang mengeluarkan laporan keuangan pada periode tertentu selalu dinantikan oleh berbagai pihak. Laporan keuangan yang dipublikasikan oleh perusahaan go public tersebut waktu pelaporannya tidak boleh melebihi dari ketentuan yang dikeluarkan oleh Bapepam yaitu 90 hari atau pada akhir bulan ketiga setelah penutupan tahun buku. Hal ini sesuai dengan keputusan Bapepam No. 36/PM/2003 tentang kewajiban laporan berkala yang menyatakan bahwa laporan keuangan tahunan disertai dengan ketepatan waktu penerbitan laporan keuangan audit merupakan hal yang sangat penting khususnya bagi perusahaan-perusahaan publik yang menggunakan pasar modal sebagai salah satu sumber pendanaannya. Namun, auditor juga memerlukan waktu untuk mengumpulkan bukti-bukti kompeten yang dapat mendukung opininya.

Selisih waktu antara tanggal tutup tahun buku dengan tanggal pelaporan auditor dalam laporan keuangan audit menunjukkan lamanya waktu penyelesaian audit yang dilakukan oleh auditor. Perbedaan waktu ini dalam auditing disebut audit delay. Semakin lama audit delay maka semakin lama auditor menyelesaikan pekerjaan auditnya (Puspitasari, E. \& Sari, A.N., 2012). 
Audit delay didefinisikan sebagai lamanya waktu penyelesaian audit yang diukur dari tanggal penutupan tahun buku hingga tanggal diterbitkannya laporan audit (Halim, 2000). Aryati (2005) menyatakan audit delay sebagai rentang waktu penyelesaian laporan audit laporan keuangan tahunan, diukur berdasarkan lamanya hari yang dibutuhkan untuk memperoleh laporan keuangan auditor independen atas audit laporan keuangan perusahaan sejak tanggal tutup buku perusahaan, yaitu per 31 Desember sampai tanggal yang tertera pada laporan auditor independen. Audit delay yang melewati batas waktu ketentuan Bapepam dan LK, tentu berakibat pada keterlambatan publikasi laporan keuangan. Beberapa hal yang perlu diperhatikan agar publikasi laporan keuangan tepat waktu antara lain; ukuran perusahaan, opini audit, reputasi kantor akuntan publik dari hasil audit periode sebelumnya.

Beberapa peneliti terdahulu menyebutkan ketepatan waktu dalam penyelesaian penyajian laporan keuangan auditor independen tersebut dengan istilah audit delay. Berikutnya faktor yang diperkirakan berpengaruh terhadap audit delay yaitu opini audit. Opini audit diperkirakan memengaruhi audit delay. Audit delay semakin panjang jika perusahaan memperoleh pendapat wajar dengan pengecualian (qualified opinion). Sementara pada perusahaan yang memperoleh pendapat wajar tanpa pengecualian (unqualified opinion) mempunyai waktu audit yang lebih cepat (Ratnawaty dan Toto Sugiharto, 2005).

Faktor yang diperkirakan dapat memengaruhi audit delay selain opini audit yaitu Reputasi Kantor Akuntan Publik (KAP). Kantor Akuntan Publik (KAP) adalah suatu bentuk organisasi akuntan publik yang memperoleh izin sesuai dengan peraturan perundang-undangan, yang berusaha di bidang pemberian jasa profesional dan dalam praktik akuntan publik (Puspitasari, E. \& Sari, A.N., 2012). Pengukuran KAP dibagi men- jadi dua yaitu KAP the big four dan KAP non big four. Hal tersebut menunjukkan reputasi dari KAP tersebut. Reputasi KAP dikatakan dapat berpengaruh positif terhadap audit delay (Rachmawati, 2008). Ivena (2012) dan Oviek Dewi (2012) menyatakan faktor reputasi KAP berpengaruh negatif terhadap audit delay. Hasil ini tidak sejalan dengan penelitian Ahmad dan Kamarudin (2000) yang menyatakan bahwa reputasi KAP mempunyai pengaruh positif terhadap audit delay.

\section{TUJUAN PENELITIAN}

Tujuan yang ingin dicapai dari penelitian ini adalah sebagai berikut.

1. Untuk menginvestigasi pengaruh secara simultan antara ukuran perusahaan, opini audit, dan reputasi kantor akuntan publik terhadap audit delay pada perusahaan pertambangan yang terdaftar di BEI periode 2010-2016.

2. Untuk menginvestigasi pengaruh ukuran perusahaan terhadap audit delay pada perusahaan pertambangan yang terdaftar di BEI periode 2010-2016.

3. Untuk menginvestigasi pengaruh opini audit terhadap audit delay pada perusahaan pertambangan yang terdaftar di BEI periode 20102016.

4. Untuk menginvestigasi pengaruh reputasi kantor akuntan publik terhadap audit delay pada perusahaan pertambangan yang terdaftar di BEI periode 2010-2016.

\section{METODE PENELITIAN}

\section{Jenis dan Sumber Data}

Penelitian ini menggunakan pendekatan kuantitatif dengan data sekunder. Secara umum, pendekatan kuantitatif lebih fokus pada tujuan untuk generalisasi, dengan melakukan pengujian. 
Yusi Nur Irmalia, Hidayatul Khusnah, Endah Tri Wahyuningtyas, Analisis Dampak Ukuran Perusahaan, Opini Audit, dan Reputasi Kap terhadap Audit Delay pada Perusahaan Pertambangan yang Terdaftar di Bei Periode 2010-2016

\section{Populasi dan Sampel}

Populasi yang digunakan dalam penelitian ini adalah seluruh perusahaan pertambangan yang telah go public dan terdaftar di Bursa Efek Indonesia untuk periode waktu 2010, 2011, 2012, 2013, 2014, 2015, dan 2016.

Sampel pada penelitian ini adalah laporan keuangan pada periode 2010-2016. Per 31 Desember 2016 jumlah Perusahaan Pertambangan yang terdaftar di BEI saat ini sebanyak 19 SUB. Teknik pengambilan sampel yang digunakan dalam penelitian ini adalah purposive sampling yaitu pemilihan sampel tidak acak yang informasinya diperoleh dengan pertimbangan atau kriteria tertentu. Kriteria tersebut yaitu perusahaan tersebut telah menerbitkan laporan keuangan selama tujuh tahun berturut-turut dari tahun 2010, 2011, 2012, 2013, 2014, 2015, dan 2016 yang telah dipublikasikan.

\section{Metode Pengolahan}

Metode analisis data dalam penelitian ini menggunakan teknik analisis kuantitatif. Analisis kuantitatif dilakukan dengan cara menganalisis permasalahan yang diwujudkan dengan data yang dapat dijelaskan secara kuantitatif. Dalam penelitian ini, analisis kuantitatif dilakukan dengan cara mengualifikasi data-data penelitian sehingga menghasilkan informasi yang dibutuhkan dalam analisis data. Data yang digunakan dalam penelitian ini adalah data yang diperoleh dari BEI (Bursa Efek Indonesia) tahun 2010-2016.

\section{Metode Analisis}

Metode analisis yang digunakan dalam penelitian ini adalah analisis regresi logistik. Analisis logistik digunakan untuk menganalisis data kuantitatif dengan bantuan SPSS.

\section{HASIL DAN PEMBAHASAN}

\section{Uji Hipotesis}

Pengujian hipotesis menggunakan model logistic regression dengan metode enter pada tingkat signifikansi $( \pm) 5 \%$. Logistic regression digunakan untuk menguji ukuran perusahaan yang diproksi dengan total asset (X1), opini audit dengan kode dummy (X2), reputasi KAP afiliasi dengan KAP big four (X3).

\section{Menilai Keseluruhan Model (Overall Model Fit)}

Ditunjukkan uji kelayakan dengan memperhatikan angka pada awal -2 log likelihood (LL) block number $=1$, sebesar 135.028, angka pada -2 log likelihood (LL) block number $=2$, sebesar 133.065, dan angka pada -2 log likelihood (LL) block number = 3-4-5, masing-masing sebesar 133.032. Hal ini menunjukkan terjadinya penurunan nilai -2 log likelihood di block 2 dan block 3 sebesar 133.065-133.032 =0.033 dan mempunyai signifikansi $0,000<0,05$ yang signifikan. Artinya bahwa secara keseluruhan model regresi logistik yang digunakan merupakan model yang baik.

\section{Uji Wald}

Variabel independen nilai $\mathrm{P}$ value uji wald (sig) $<0,05$ artinya variabel tersebut mempunyai pengaruh parsial yang signifikan terhadap Y. X1 mempunyai nilai sig wald 0,161 >0,05 sehingga menerima $\mathrm{H} 0$ atau berarti $\mathrm{X} 1$ tidak memberikan pengaruh parsial terhadap Y. X2 mempunyai nilai sig wald $0,000<0,05$ sehingga menolak $\mathrm{H} 0$ atau berarti X2 memberikan pengaruh parsial yang signifikan terhadap Y. X3 mempunyai nilai sig wald $0,000<0,05$ sehingga menolak $\mathrm{H} 0$ atau berarti X3 memberikan pengaruh parsial yang signifikan terhadap $\mathrm{Y}$. 


\section{Koefisien Determinasi (Nagelkerke R Square)}

Untuk melihat kemampuan variabel independen dalam menjelaskan variabel dependen, digunakan nilai cox \& snell $R$ square dan nagelkerke $R$ square. Nilai-nilai tersebut disebut juga dengan pseudo R-square atau jika pada regresi linear (OLS) lebih dikenal dengan istilah $R$-square.

Nilai nagelkerke $R$ square sebesar 0,377 dan cox \& snell $R$ square 0,277 , yang menunjukkan bahwa kemampuan variabel independen dalam menjelaskan variabel dependen adalah sebesar 0,377 atau 37,7\% dan terdapat 100\% $37,7 \%=62,3 \%$ faktor lain di luar model yang menjelaskan variabel dependen.

\section{Menguji Kelayakan Model Regresi}

Kelayakan model regresi dinilai dengan menggunakan hosmer and lemeshow's goodness of fit test. Hosmer and lemeshow test adalah uji goodness of fit test (GoF), yaitu uji untuk menentukan apakah model yang dibentuk sudah tepat atau tidak. Dikatakan tepat apabila tidak ada perbedaan signifikan antara model dengan nilai observasinya.

Nilai chi square tabel untuk DF 8 pada taraf signifikansi 0,05 sebesar 15.50731306 . Karena nilai chi square hosmer and lemeshow hitung $7.711<$ chi square table 15.50731306 atau nilai signifikansi sebesar 0,462 $(>0,05)$ sehingga menerima $\mathrm{H} 0$, yang menunjukkan bahwa model dapat diterima dan pengujian hipotesis dapat dilakukan sebab tidak ada perbedaan signifikan antara model dengan nilai observasinya.

\section{Uji Multikolonieritas}

Model regresi yang baik adalah regresi dengan tidak adanya gejala korelasi yang kuat di antara variabel bebasnya. Pengujian ini menggunakan matriks korelasi antar-variabel bebas untuk melihat besarnya korelasi antar-variabel independen.

Hasil menunjukkan tidak ada nilai matriks korelasi antar-variabel yang lebih besar dari 0,9. Apabila terjadi hal yang demikian, maka tidak ada gejala multikolinieritas yang serius antar variabel bebas.

\section{Matriks Klasifikasi}

Matriks klasifikasi menunjukkan kekuatan prediksi dari model regresi untuk memprediksi kemungkinan adanya audit delay lebih dari 90 hari yang dilakukan perusahaan.

Berdasarkan classification table, jumlah sampel yang audit delay 0 sebanyak $26+24=50$. Yang benar-benar audit delay 0 adalah 26 dan yang seharusnya audit delay 0 namun berubah menjadi 1 , sebanyak 24. Maka ketepatan model adalah $26 / 50=52,0 \%$.

Jumlah sampel yang audit delay 1 sebanyak $8+75=83$. Yang benar-benar audit delay 1 sebanyak 75 dan yang seharusnya audit delay 1 menjadi 0 sebanyak 8 . Maka ketepatan model adalah $75 / 83=90,4 \%$. Tabel di atas memberikan nilai overall percentage sebesar $(26+75) / 133=$ $75,9 \%$ yang berarti ketepatan model penelitian ini adalah sebesar 75,9\%.

\section{Model Regresi Logistik yang Terbentuk}

Tahap akhir pengujian ini adalah uji koefisiensi regresi, di mana pada pengujian ini kita dapat mengetahui sejauh mana suatu variabel independen berpengaruh terhadap variabel dependen. Adapun variabel yang digunakan adalah penerapan ukuran perusahaan (X1), opini audit (X2), dan reputasi KAP (X3), sedangkan variabel dependennya audit delay. 
Yusi Nur Irmalia, Hidayatul Khusnah, Endah Tri Wahyuningtyas, Analisis Dampak Ukuran Perusahaan, Opini Audit, dan Reputasi Kap terhadap Audit Delay pada Perusahaan Pertambangan yang Terdaftar di Bei Periode 2010-2016

Hasil pengujian dengan regresi logistik pada tingkat signifikan 5 persen. Dari pengujian persamaan regresi logistik tersebut maka diperoleh model regresi logistik sebagai berikut.

Ln $\mathrm{P} / 1-\mathrm{P}=0,760-0,088 \mathrm{X} 1+1,800 \mathrm{X} 2+$ $1,789 \times 3$.

Atau bisa menggunakan rumus turunan dari persamaan di atas sebagai berikut.

Probabilitas $=\exp (0,760-0,088 \mathrm{X} 1+1,800$ $\mathrm{X} 2+1,789 \mathrm{X} 3) / 1+\exp (0,760$ $-0,088 \mathrm{X} 1+1,800 \mathrm{X} 2+1,789$ $\mathrm{X} 3$ ).

$\mathrm{H}_{1}$ : Ukuran perusahaan, opini audit, dan reputasi kantor akuntan publik berpengaruh positif secara simultan terhadap audit delay.

Jawaban terhadap hipotesis pengaruh simultan variabel independen terhadap variabel dependen adalah menerima $\mathrm{H} 1$ dan menolak $\mathrm{H} 0$ atau yang berarti ada pengaruh signifikan secara simultan semua variabel bebas terhadap Y oleh karena nilai p value chi-square sebesar $0,000 \mathrm{di}$ mana $<$ alpha 0,05 atau nilai chi-square hitung 43.071 > chi-square tabel 7.814727903.

Hal ini mengindikasikan bahwa variabel bebas yang digunakan dalam penelitian yaitu ukuran perusahaan, opini auditor dan reputasi kantor akuntan publik secara bersama-sama (simultan) berpengaruh terhadap audit delay. Hasil penelitian ini sesuai dengan penelitian terdahulu Iskandar (2013), Tiono dan Jogi (2013), dan Puspitasari dan sari (2013).

$\mathrm{H}_{2}$ : Ukuran perusahaan berpengaruh positif terhadap audit delay.

Hasil regresi pada ukuran perusahaan (size) menunjukkan nilai koefisien $-0,088$ yang berarti variabel ini menunjukkan arah negatif antara ukuran perusahaan dengan audit delay. Variabel $\mathrm{X} 1$ nilai signifikansinya $0,916 \mathrm{di}$ atas signifikansi
0,05 (5\%). Hal ini mengandung arti bahwa hipotesis ke-2 dinyatakan tidak berhasil didukung.

Penelitian ini senada dengan penelitian sebelumnya yang dilakukan oleh Margaretta (2011), Ferdianto (2011), Kartika (2009), yang menyatakan bahwa ukuran perusahaan tidak memiliki pengaruh terhadap audit delay.

$\mathrm{H}_{3}$ : Opini audit berpengaruh positif terhadap audit delay

Dari data penelitian diketahui bahwa dari 133 perusahaan sampel, 87 perusahaan memperoleh unqualified opinion dan sebanyak 46 perusahaan memperoleh pendapat qualified opinion. Kondisi tersebut yang menyebabkan hasil penelitian ini menjadi signifikan dan sesuai dengan logika teori. Hasil penelitian ini mendukung hasil penelitian yang dilakukan oleh Hilmi dan Ali (2008) dan Sudaryanti (2009) yang menyatakan bahwa opini auditor berpengaruh terhadap audit delay.

$\mathrm{H}_{4}$ : Reputasi KAP berpengaruh positif terhadap audit delay

Hasil regresi pada reputasi KAP menunjukkan nilai koefisien regresi sebesar 1.789 dengan probabilitas variabel sebesar 0,000 di bawah signifikansi 0,05 (5\%). Hal ini mengandung arti bahwa $\mathrm{H} 4$ diterima, dengan demikian terbukti bahwa reputasi KAP berpengaruh terhadap $a u-$ dit delay.

Demikian arah koefisien regresi pada reputasi KAP dalam penelitian ini bertanda positif. Hasil pengujian hipotesis 4 menunjukkan bahwa KAP mempunyai pengaruh yang positif dan signifikan terhadap audit delay. Hasil ini mendukung pada penelitian Ahmad dan Kamarudin (2000), Utami (2006), dan Rachmawati (2009) yang menyatakan bahwa ukuran KAP mempunyai pengaruh signifikan terhadap audit delay. Hasil 
ini menunjukkan bahwa auditor yang mempunyai reputasi yang baik (KAP big four) akan memberikan kualitas pekerjaan audit yang efektif dan efisien, sehingga audit dapat diselesaikan secara tepat waktu. KAP big four memperoleh insentif lebih tinggi untuk menyelesaikan pekerjaan audit lebih cepat juga merupakan cara KAP big four mempertahankan reputasinya.

\section{KESIMPULAN}

Berdasarkan hasil analisis regresi logistik, hasil penelitian yang telah dilakukan mengenai dampak yang memengaruhi audit delay, di mana yang dimaksud adalah ukuran perusahaan (LnSize), opini audit (dummy), reputasi KAP (big four). Maka dapat ditarik beberapa kesimpulan sebagai berikut.

1. Ukuran perusahaan, opini audit, dan reputasi KAP berpengaruh positif secara simultan terhadap audit delay.

2. Ukuran perusahaan tidak memiliki pengaruh yang positif terhadap audit delay.

3. Opini audit memiliki pengaruh yang positif terhadap audit delay.

4. Reputasi KAP memiliki pengaruh yang positif terhadap audit delay.

\section{SARAN}

Berdasarkan hasil dan keterbatasan dalam penelitian ini maka dapat diberikan saran sebagai berikut.

1. Bagi perusahaan pertambangan pada hasil penelitian ini yang berpengaruh signifikan terhadap audit delay adalah variabel opini audit dan reputasi KAP. Diharapkan pihak manajemen perusahaan memperhatikan dua faktor tersebut agar dapat mengurangi audit delay dalam pelaporan keuangan.
2. Diharapkan peneliti selanjutnya memakai variabel bebas, seperti likuiditas, solvabilitas, profitabilitas, dan pergantian auditor.

3. Proksi yang digunakan untuk variabel independen tidak hanya satu proksi saja. Agar hasil yang diperoleh dapat lebih baik dan lebih luas lagi daripada penelitian ini.

4. Menggunakan data yang lebih baik lagi. Misalnya, data laporan keuangan yang bersumber dari perusahaan-perusahaan yang diteliti.

\section{DAFTAR RUJUKAN}

Aditya, A.N. \& Anisykurlillah, I. 2014. Faktorfaktor yang Berpengaruh terhadap Audit Delay. Accounting Analysis Journal, 3(3).

Ahmad, R.A.R. \& Kamarudin, K.A. 2003. Audit Delay and the Timeliness of Corporate Reporting: Malaysian Evidence. In Communication Hawaii International Conference on Business. June, University of $\mathrm{Ha}$ waii-West Oahu.

Angruningrum, S. \& Wirakusuma, M.G. 2013. Pengaruh Profitabilitas, Leverage, Kompleksitas Operasi, Reputasi KAP dan Komite Audit Pada Audit Delay. e-Jurnal Akuntansi, 5(2), 251-270.

Aryati, T. 2009. Faktor-Faktor yang Memengaruhi Audit Delay dan Timeliness. Media Riset Akuntansi, Auditing dan Informasi, 5(3), 271-287.

Azhari, M. 2014. Faktor-Faktor yang Memengaruhi Audit Delay (Study Kasus pada Perusahaan Perbankan yang Terdaftar di Bursa Efek Indonesia). Doctoral Dissertation. Surabaya: STIESIA.

Dewi, K.M. \& Pamudji, S. 2013. Analisis FaktorFaktor yang Memengaruhi Ketepatan Waktu dan Audit Delay Penyampaian Laporan Keuangan (Studi Empiris pada 
Yusi Nur Irmalia, Hidayatul Khusnah, Endah Tri Wahyuningtyas, Analisis Dampak Ukuran Perusahaan, Opini Audit, dan Reputasi Kap terhadap Audit Delay pada Perusahaan Pertambangan yang Terdaftar di Bei Periode 2010-2016

Perusahaan Manufaktur yang Terdaftar di BEI Periode 2007-2011). Doctoral dissertation, Fakultas Ekonomika dan Bisnis.

Dyer, J.C. \& McHugh, A.J. 1975. The Timeliness of the Australian Annual Report. Journal of Accounting Research, 204-219.

Estrini, Dwi Hayu dan Herry Laksito. 2013. "Analisis Faktor-Faktor yang Memengaruhi Audit Delay (Study Empiris pada Perusahaan Manufaktur yang terdaftar di BEI Tahun 2009-2011)". Diponegoro Journal of Accounting, Vol. 2, No. 2.

Halim, V. 2000. Faktor-Faktor yang Memengaruhi Audit Delay: Studi Empiris pada Perusahaan-Perusahaan di Bursa Efek Jakarta. Jurnal Bisnis dan Akuntansi, 2(1), 63-75.

Hutomo, E.Y. 2015. Pengaruh Ukuran Perusahaan, Profitabilitas, Solvabilitas, dan Opini Audit Terhadap Audit Delay (Studi pada Perusahaan Pertambangan yang Terdaftar di Bursa Efek Indonesia Periode 20102013. Doctoral Dissertation, Fakultas Ekonomi Unpas.

Iskandar, M.J. \& Trisnawati, E. 2010. FaktorFaktor yang Memengaruhi Audit Report Lag pada Perusahaan yang Terdaftar di Bursa Efek Indonesia. Jurnal Bisnis dan Akuntansi, 12(3), 175-186.

Kartika, A. 2011. Faktor-Faktor yang Memengaruhi Audit Delay pada Perusahaan Manufaktur yang Terdaftar di BEI. Dinamika Keuangan dan Perbankan, 3(2).

Kusumawardani, F. 2013. Faktor-Faktor yang Memengaruhi Audit Delay pada Perusahaan Manufaktur. Accounting Analysis Journal, 2(1).

Lestari, D. \& Lestari, D. 2010. Analisis Faktor-Faktor yang Memengaruhi Audit Delay: Studi Empiris pada Perusahaan Consumer Goods yang Terdaftar di Bursa
Efek Indonesia. Doctoral Dissertation, Universitas Diponegoro.

Lianto, N. \& Kusuma, B.H. 2010. Faktor-Faktor yang Berpengaruh terhadap Audit Report Lag. Jurnal Bisnis dan Akuntansi, 12(2), 97-106.

Margaretta S. 2011. Pengaruh Penerapan IFRS Terhadap Keterlambatan Waktu Penyampaian Laporan Keuangan pada Perusahaan Manufaktur yang Terdaftar di Bursa Efek Indonesia pada Tahun 2008-2010. Doctoral Dissertation, BINUS.

Masian, I.C.I. 2017. Faktor-Faktor yang Memengaruhi Audit Delay Pasca-Implementasi Ifrs Berdasarkan Karakteristik Perusahaan dan Kualitas Audit (Studi Empiris Perusahaan Manufaktur dan Perbankan Terdaftar di BEI 2010-2015. Doctoral dissertation, FE UMY.

Mawardi, R. 2016. Internal and External Company's Factors on Audit Delay Study from Indonesia Stock Exchange.

Modugu, P.K., Eragbhe, E., \& Ikhatua, O.J. 2012. Determinants of Audit Delay in Nigerian Companies: Empirical evidence. Research Journal of Finance and Accounting, 3(6), 46-55.

Oviek, D. 2012. Analisis Faktor-Faktor yang Memengarubi Audit Delay (Studi Empiris pada Perusahaan-Perusahaan yang Terdaftar di Bursa Efek Indonesia).

Paramitasari, R., Astuti, B.C., \& Dawam, M. 2013. Analisis Faktor-Faktor yang Memengaruhi Audit Delay pada Perusahaan Lq45 yang Terdaftar di Bursa Efek Indonesia.

Prahesty, S., \& Pamudji, S. 2011. Analisis FaktorFaktor yang Memengaruhi Ketepatan Waktu Pelaporan Keuangan (Studi Empiris pada Perusahaan Food and Beverages di Bursa Efek Indonesia Periode Tahun 2004- 
2009. Doctoral dissertation, Universitas Diponegoro).

Pramesti, H. \& Dananti, K. 2012. Analisis Faktor-Faktor Audit Delay Perusahaan Manufaktur dan Finansial di Bursa Efek Indonesia. Jurnal Akuntansi dan Sistem Teknologi Informasi, 9(1), 11-22.

Puspitasari, E. \& Sari, A.N. 2012. Pengaruh Karakteristik Perusahaan Terhadap Lamanya Waktu Penyelesaian Audit (Audit Delay) pada Perusahaan Manufaktur yang Terdaftar di Bursa Efek Indonesia. Jurnal Akuntansi dan Auditing, 9(1), 3142.

Rachmawati, S. 2009. Pengaruh Faktor Internal dan Eksternal Perusahaan Terhadap Audit Delay dan Timeliness. Jurnal Akuntansi dan Keuangan, 10(1), PP-1.

Ratnawaty, R. \& Sugiharto, T. 2005. Audit Delay pada Industri Real Estate dan Properti yang Terdaftar di Bursa Efek Jakarta dan Faktor yang Memengaruhi. In Proceeding, Seminar Nasional PESAT 2005. Universitas Gunadarma.

Respati, N.W. 2001. Faktor-Faktor yang Berpengaruh Terhadap Ketepatan Waktij Pelaporan Keuangan: Studi Empiris di Bursa Efek Jakarta. Doctoral Dissertation, Program Pascasarjana Universitas Diponegoro.

Rochmah Ika, S. \& Mohd Ghazali, N.A. 2012. Audit Committee Effectiveness and Timeliness of Reporting: Indonesian Evidence. Managerial Auditing Journal, 27(4), 403424.

Saputri, O.D. \& Yuyetta, E.N.A. 2012. Analisis Faktor-Faktor yang Memengaruhi Audit Delay (Studi Empiris pada PerusahaanPerusahaan yang Terdaftar di Bursa Efek Indonesia). Doctoral Dissertation, Fakultas Ekonomika dan Bisnis.
Sari, I.P., Satriawan, R.A., \& Ilham, E. 2015. Pengaruh Ukuran Perusahaan, Solvabilitas dan Reputasi Kap Terhadap Audit Delay pada Perusahaan Property \& Real Estate di Bursa Efek Indonesia periode 20092012. Jurnal Online Mahasiswa (JOM) Bidang Ilmu Ekonomi, 1(2), 1-15.

Sunaningsih, S.N. \& Rohman, A. 2014. FaktorFaktor yang Berpengaruh Terhadap Audit Delay (Studi Empiris pada Perusahaan Sektor Jasa yang Terdaftar di Bursa Efek Indonesia Periode Tahun 2011 dan 2012). Doctoral Dissertation, Fakultas Ekonomika dan Bisnis.

Tiono, I. 2013. Faktor-Faktor yang Memengaruhi Audit Report Lag di Bursa Efek Indonesia. Business Accounting Review, 1(2), 286-297.

Trisnawati, Estralita dan Charistine. 2008. Pengaruh Opini Audit, Rasio Profitabilitas, Solvabilitas, dan Ukuran KAP Terhadap Audit Delay. Jurnal Akuntansi, Vol 8, hlm. $107-126$

Utami, W. 2006. Analisis Determinan Audit Delay Kajian Empiris di Bursa Efek Jakarta. Bulletin Penelitian, 9.

www.cnnindonesia.com diakses pada tanggal 9 November 2017.

www.idx.co.id diakses pada tanggal 9 November 2017.

www.ojk.go.id diakses pada tanggal 26 September 2017.

www.sahamok.com diakses pada tanggal 26 September 2017.

Yaacob, N.M. \& Che-Ahmad, A. 2012. Adoption of FRS 138 and Audit Delay in Malaysia. International Journal of Economics and Finance, 4(1), 167. 